\title{
IN-SITU DRIFT SPECTROSCOPY IN A CONTINUOUS RECYCLE REACTOR: A VERSATILE TOOL FOR CATALYTIC PROCESS RESEARCH
}

\author{
J.G.Highfield*, M.Prairie ${ }^{* *}$ and A.Renken ${ }^{* * *}$ \\ * Paul Scherrer Institute, CH-5232 Villigen PSI, Switzerland. \\ ** Sandia National Laboratories, Albuquerque N.M. 87185, U.S.A. \\ *** Swiss Federal Institute of Technology, CH-1015 Lausanne, Switzerland.
}

\begin{abstract}
Diffuse Reflectance Infrared Fourier-Transform (DRIFT) spectroscopy is an increasingly popular technique in catalysis research as it permits in-situ observation of the reactor bed in powdered or granular form. However, DRIFTS in its conventional form suffers from temperature-gradient problems. One solution is to couple the DRIFTS cell with a continuous recycle flow system. The value of such an arrangement is illustrated via studies of the kinetics and mechanism of $\mathrm{CO}_{2}$ methanation over $\mathrm{Ru} / \mathrm{TiO}$ under transient and steadystate conditions. Metal-adsorbed $\mathrm{CO}$ is identified as the main reaction intermediate through titration to $\mathrm{CH}_{4}$ in transient hydrogenation. The $\mathrm{CO}_{2 \mathrm{~d}}$ is probably supplied via rapid establishment of the reverse water gas shift equilibrium:

involving adsorbed formate intermediate(s).$$
\mathrm{H}_{2}+\mathrm{CO}_{2} \rightarrow \mathrm{CO}_{\mathrm{ad}}+\mathrm{H}_{2} \mathrm{O}
$$

\section{INTRODUCTION}

Transmission infrared spectroscopy is a valuable technique in catalytic science for the insitu detection and characterization of intermediates sorbed on the surface of heterogeneous catalysts (in the form of pressed-discs) under realistic conditions, i.e. high temperatures and/or high pressures. However, the drawbacks of this method are well-documented(1,2). The recent advent of commercial FTIR spectrometers, with their inherent advantages of speed and sensitivity, has led to the rapid development of alternative methods, among which Diffuse-Reflectance IR Fourier-Transform Spectroscopy (DRIFTS) permits observation of the catalyst directly in powdered or granular form(3) and appears to offer good prospects for in-situ applications, as reflected in the rapid growth of literature on this topic (see e.g. refs.4-9).

DRIFTS circumvents many of the problems associated with the pressed-disc approach as described above but suffers from one particular weakness in its conventional form of application, viz. thermal gradients across the catalyst bed(6). These arise primarily from the optical constraints of the reflectance mode, which require that the sample be heated from underneath, and the fact that particulate solids are notoriously poor thermal conductors.

Coupling the DRIFTS cell with a continuous recycie flow system effectively overcomes this problem by allowing the incorporation of a large conventional reactor in the recirculation loop. As the catalytic behaviour is now controlled essentially by the latter, the sample size in the DRIFTS cell can be reduced (together with the associated temperature grad- 
ients) to a limit controlled only by optical sensitivity factors, i.e. the IR beam diameter in the focal plane and the beam penetration (analytical) depth, both typically only $\approx 1-2 \mathrm{~mm}$. Provided good temperature-matching of the two catalyst charges is maintained, the DRIFT cell can be regarded as a window into the reactor, providing a representative view of the entire catalyst surface under process conditions. Additional benefits accrue from the fundamental versatility of the recycle reactor, e.g in yielding meaningful kinetic parameters at high conversion when operated under differential conditions, and, by the same token, easier on-line reaction monitoring(10).

External recycle loops have been exploited before in catalytic studies by $\mathbb{R}$ but using the conventional transmission arrangement. Tamaru (11) has described a batch recirculation apparatus and Kaul and Wolf (12) have more recently examined thermal transport problems in pressed-discs and their relation to gas-flow characteristics. The extension of the principle to the DRIFTS technique, in which the catalyst state more closely approximates that used in a technical (fixed-bed reactor) application, thus represents an obvious advance but one which has not been reported on elsewhere to the knowledge of these authors. The value of such a configuration is illustrated via a study of the kinetics and mechanism of $\mathrm{CO}_{2}$ methanation over $\mathrm{Ru} / \mathrm{TiO}_{2}$ under both transient and steady-state conditions in the temperature range $120-200^{\circ} \mathrm{C}$ and for conversions up to $70 \%$. The Sabatier process:

$$
\mathrm{CO}_{2}+4 \mathrm{H}_{2} \rightarrow \mathrm{CH}_{4}+2 \mathrm{H}_{2} \mathrm{O}
$$

was chosen as a model reaction as it is known to be interesting from the viewpoint of $\mathrm{IR}$ spectroscopy(13-15); a highly-active catalyst has been under development and testing at this Institute ${ }^{* * *}(7,16)$, and $\mathrm{CO}_{2}$ activation and conversion to valuable fuels and chemicals is a topic of global interest $(17,18)$.

\section{EXPERIMENTAL}

The catalyst consisted of $\mathrm{Ru}$ (3.8wt.\%) dispersed on $\mathrm{TiO}_{2}$ (Degussa P25) as fine particles, $\mathrm{d}=10-20 \AA$. Its preparation and characterization have been described elsewhere $(7,16)$.

The experimental set-up is represented schematically in Fig.1. A fixed-bed reactor was coupled to the DRIFTS cell in an extemal flow loop together with a recycle pump. Gases were supplied from two banks of mass flow controllers via a micro-volume four-way valve, across which the differential pressure was maintained at zero ( for flow-switching in transient operation). Oxygen impurities were removed from the feed gases $\mathrm{Ar}, \mathrm{H}_{2}, \mathrm{CO}_{2}$ and $\mathrm{CO}$ using on-line self-indicating traps $\left(\mathrm{Oxisorb} \mathrm{R}^{\mathrm{R}},<0.1 \mathrm{ppm} \mathrm{O}_{2}\right)$. Formic acid was introduced as vapour by bubbling Ar through the liquid as supplied. Effluent from the reactor was sampled directly and continuously through a two-stage pressure-reduction valve into a Balzers QMG420 quadrupole mass spectrometer operating at $10^{-7} \mathrm{mbar}$, calibrated for $\mathrm{CH}_{4}$ at $\mathrm{m} / \mathrm{e}=15$. The reactor pressure was typically set at 1.4 bar with a back-pressure regulator in order to smooth out small pressure fluctuations introduced by the recycle pump. The latter was of the oscillating membrane type (KNF,mod.N026.11E) having an internal volume of $1 \mathrm{~cm}^{3}$, a pumping rate of $10 \mathrm{~L} \cdot \mathrm{min}^{-1}$ at $1 \mathrm{bar}$ and negligible pressure drop, and a heating unit $\left(240^{\circ} \mathrm{C}\right)$ for the recycle gas. However, under the experimental conditions imposed by the reactors and tubing, the recycle rate was limited to $2 \mathrm{~L}$ $\min ^{-1}$. As ideal mixing behaviour is approached for recycle ratios $>25$ (with conversion 
limited to $<2 \%$ per pass), this resulted in a maximum supply rate for the feed gas of $70 \mathrm{ml}$

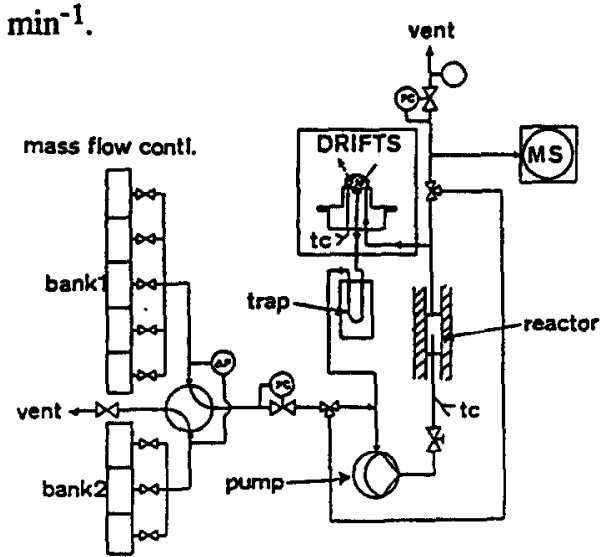

Fig.1. Schematic layout of the DRIFTS/recycle reactor experimental arrangement.

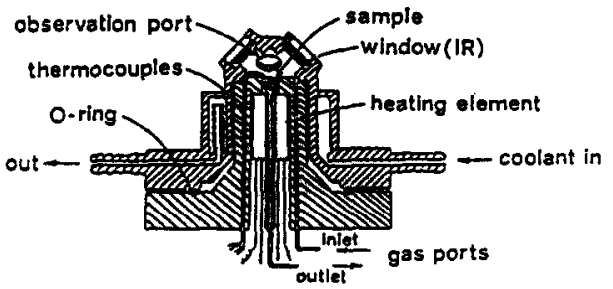

Fig.2. Schematic section through the modified commercial diffuse-reflectance cell.

The DRIFTS reactor consisted of a modified Harrick HVP vacuum chamber $(\mathrm{NaCl}$ windows) in which the base was completely replaced with one of home-made design, as depicted in Fig.2. The new base in stainless steel(s.s) was designed with the view to minimizing dead volume, effecting some preheat of the inlet gas, and better temperature definition in the sample bed. This was achieved with two $0.5 \mathrm{~mm}$ s.s. thermocouples, one located at variable depth in the catalyst close to the wall of the heating post, the other fixed at the centre $=1 \mathrm{~mm}$ below the illuminated surface. This latter was used as feedback control for bed-heating via a Eurotherm 815PID controller. At the maximum temperature used in these studies, i.e. $200^{\circ} \mathrm{C}$, the temperature difference between the two never exceeded $3^{\circ} \mathrm{C}$, even when flowing $>1 \mathrm{~L} \mathrm{~min} \mathrm{~m}^{-1}$ of gas directly through the bed.

For FTIR measurements, the cell was located in a Harrick DRA-2CO diffuse-reflectance accessory and mounted into the sample compartment of the spectrometer. For transient experiments, spectra from $4000-800 \mathrm{~cm}^{-1}$ were obtained at $8 \mathrm{~cm}^{-1}$ resolution in a Bomem DA3.002 spectrometer fitted with a short-range $\mathrm{HgCdTe}$ detector and $\mathrm{KBr}$ beamsplitter, $\mathrm{A}$ suitable program for data acquisition was found to be coaddition of 20 scans per stored spectrum (requiring $6 \mathrm{~s}$ ), and a time resolution of typically $3 \mathrm{~min}$. per spectrum. Raw spectra were converted into either relative reflectance or Kubelka-Munk form using as reference the spectrum of the clean catalyst in $\mathrm{H}_{2}$ taken at the same temperature. Steady-state data were obtained at $4 \mathrm{~cm}^{-1}$ resolution using a Nicolet 710 FTIR spectrometer equipped with the same beamsplitter/detector combination as described above.

The conventional reactor consisted of a s.s. Nupro filter holder (part no. 2F-MM) with dimensions of $10 \mathrm{~mm}$ i.d. $\times 13 \mathrm{~mm}$ long. Catalyst (typical wt. $0.5-1 \mathrm{~g}$ ) replaced the original filter and was held in place by two s.s.screens and quartz wool. Temperature control of the catalyst bed was based on a centred s.s thermocouple, and the reactor was wrapped with heating tape and well-insulated.

A cold trap ( $20 \mathrm{ml}$ glass U-tube) was introduced into the recycle loop and maintained routinely at $-30^{\circ} \mathrm{C}$ to control the steady-state water concentration and to avoid condensation in the (unheated) lines. The partial vapour pressure of water corresponding to this temperature is $\approx 300 \mathrm{ppm}$, and the effectiveness of the trap was checked up to a methanation 
reaction temperature of $160^{\circ} \mathrm{C}$, when the rate of water production was $\approx 2 \mu \mathrm{mol} . \mathrm{s}^{-1}$. Both the FTIR and mass spectrometer were used to monitor ambient water vapour levels.

Excellent backmixing for the entire recirculation system was verified via step-response tracer experiments which produced exponential response curves. A residence time, $\tau$, of 1.7 min. was observed with a feed rate of $50 \mathrm{ml} \mathrm{min}^{-1}$ ( recycle ratio $\approx 35$ ).

In preliminary work, pre-reduction of the catalyst in flowing $\mathrm{H}_{2}(20 \%$ in $\mathrm{Ar})$ at $225^{\circ} \mathrm{C}$ for 1h was found to achieve reproducible steady-state activity. However, the development of IR bands due to adsorbed intermediates was not nearly so reproducible and a pre-cleaning of the catalyst surface was necessary in flowing $\mathrm{O}_{2}$ at the same temperature for $1 \mathrm{~h}$, followed by an Ar purge prior to reduction. Small amounts of $\mathrm{CO}_{2}$ were detected in this oxidation step suggesting contamination by carbon or carbonaceous residues whose origin is uncertain. In any event, this important detail must be accommodated into any plausible mechanistic scheme as discussed later.

In the titration experiments for metal-adsorbed $\mathrm{CO}$, peak areas ( in the Kubelka-Munk form) were integrated after suitable linear interpolation of baselines under the band envelope of interest. This was quite broad, extending typically from $2100-1700 \mathrm{~cm}^{-1}$, though its form remained to a first approximation independent of coverage.

\section{RESULTS AND DISCUSSION.}

Identification of adsorbed intermediates.

The FTIR spectrum under steady-state conditions in the standard $\mathrm{CO}_{2} / \mathrm{H}_{2}$ methan -ation mixture at $120^{\circ} \mathrm{C}$ is presented in Fig.3a. A strong band characteristic of $\mathrm{CO}$ adsorbed on $\mathrm{Ru}^{0}$ in the on-top position is evident at $2035 \mathrm{~cm}^{-1}$ as reported elsewhere $(13,15,20)$. In addition, bands attrib -utable to formate ion $(15,19), \mathrm{HCOO}^{-}$, can be seen at $2940(v w), 2875(w)$, $1555(\mathrm{~s})$ and $1360(\mathrm{~s}) \mathrm{cm}^{-1}$. The main bands are assigned to the asymmetric and symmetric stretch of the $\mathrm{COO}^{-}$moiety. The weak bands at high frequency are more difficult to assign though it is generally agreed that the $2880 \mathrm{~cm}^{-1}$ band is the C-H stretch. The weakest band at

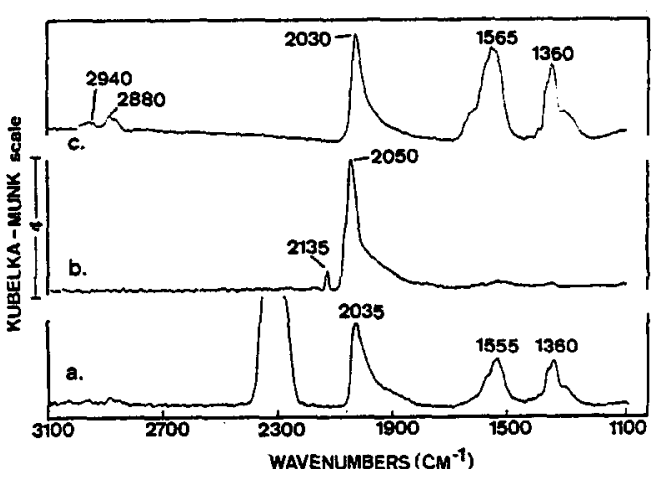

Fig.3. In-situ DRIFT spectra of adsorbed intermediates at $120^{\circ} \mathrm{C}$ : a. during steady-state methanation in $\mathrm{CO}_{2}: \mathrm{H}_{2}: \mathrm{Ar}(1: 2: 2)$; b. after $\mathrm{CO}$ adsorption on the clean catalyst for $1 \mathrm{~h}$ and Ar purge, and $\mathrm{c}$. after contacting sample in $b$ with water vapour for $1 \mathrm{~h}$.

$2940 \mathrm{~cm}^{-1}$ is possibly a combination band involving the asymmetric stretch of $\mathrm{COO}^{-}$and a $\mathrm{C}-\mathrm{H}$ deformation(21). The assignment to formate was confirmed by exposing the clean catalyst to formic acid vapour, which reproduced spectrum $3 \mathrm{a}$, including a stronger $\mathrm{CO}_{\mathrm{ad}}$ feature at $2045 \mathrm{~cm}^{-1}$. Exposure of the pure support $\left(\mathrm{TiO}_{2} \mathrm{P} 25\right)$ to $\mathrm{HCOOH}$ under the same conditions reproduced only the formate bands, while no new bands developed from contact with the methanation mixture.

It seems most likely that $\mathrm{CO}_{\mathrm{ad}}$ is formed via the reverse water-gas shift reaction:

$$
\mathrm{CO}_{2}+\mathrm{H}_{2} \rightarrow \mathrm{CO}_{\mathrm{ad}}+\mathrm{H}_{2} \mathrm{O}
$$


in which formate ion is implicated. This is consistent with most other reports in the literature $(13,19,22)$. The possibility that formate is an intermediate in the overall methanation process has been tested recently in a batch reactor in which the $\mathrm{CH}_{4}$ was monitored directly by FTIR(23). Relative initial rates for $\mathrm{CO}_{2} / \mathrm{H}_{2}$ and $\mathrm{HCOOH} / \mathrm{H}_{2}$ mixtures were found to be virtually identical, showing that the preliminary step of $\mathrm{CO}_{2}$ reduction to formate is not rate-determining.

For more information, $\mathrm{CO}$ was pre-adsorbed directly on the clean catalyst to produce spectrum $3 \mathrm{~b}$. The very strong band at $2051 \mathrm{~cm}^{-1}$ evidently corresponds to the weaker band at $2035 \mathrm{~cm}^{-1}$ produced from the methanation mixture. Coverage-dependent frequency shifts of this order are well-known for metal-adsorbed CO, and are interpreted in terms of dynamic and static adsorbate-adsorbate interactions(24). The tail absorption to lower frequency indicates a fraction of $\mathrm{CO}$ in bridging sites, whilst the small band at $2135 \mathrm{~cm}^{-1}$ is possibly due to linearly-adsorbed $\mathrm{CO}$ on $\mathrm{Ru}$ in a non-zero oxidation state, e.g. $\mathrm{Ru}^{3+}(20)$. Recent epr studies of this catalyst provide evidence for two types of $\mathrm{Ru}^{3+}$ species upon mild reduction in $\mathrm{H}_{2}$, one associated with the support and the other with $\mathrm{RuO}_{\mathrm{x}}(\mathrm{x}<2)$ islands(25).

To illustrate the remarkable activity of the catalyst for the water-gas shift reaction, the preadsorbed $\mathrm{CO}$ was subsequently exposed to water vapour (simply by warming the trap). This caused the almost instantaneous appearance of formates at the expense of some $\mathrm{CO}_{\mathrm{ad}}$ (see Fig.3, spectrum c). However, long-term (a few h) exposure had little further effect suggesting either auto-inhibition by $\mathrm{HCOO}_{\mathrm{ad}}$, or equilibrium control due to stronglybound $\mathrm{CO}$.

The role of $\mathrm{CO}_{\mathrm{ad}}$ in producing methane is best illustrated in transient experiments. After accumulation of $\mathrm{CO}_{\mathrm{ad}}$ (and formate) from the $\mathrm{Ar} / \mathrm{CO}_{2} / \mathrm{H}_{2}$ mixture at $120^{\circ} \mathrm{C}$, the flow was switched to $\mathrm{H}_{2}$ (40 mol.\% in Ar). The qualitative correspondence in the decay rate of the IR bands of interest and the level of $\mathrm{CH}_{4}$ in the effluent is clearly demonstrated in Fig.4.
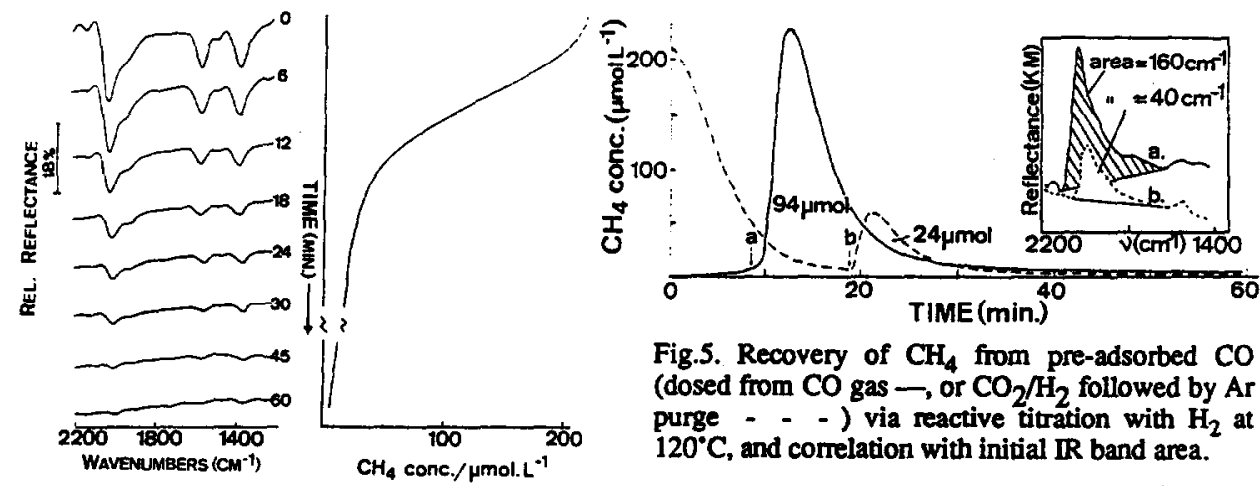

Fig.5. Recovery of $\mathrm{CH}_{4}$ from pre-adsorbed $\mathrm{CO}$ (dosed from $\mathrm{CO}$ gas - or $\mathrm{CO}_{2} / \mathrm{H}_{2}$ followed by $\mathrm{Ar}$ purge - - -) via reactive titration with $\mathrm{H}_{2}$ at $120^{\circ} \mathrm{C}$, and correlation with initial IR band area.

Fig.4. Correlation of decay kinetics of DRIFT spectral features at $120^{\circ} \mathrm{C}$ with $\mathrm{CH}_{4}$ level in the effluent after flow-switching from $\mathrm{CO}_{2}: \mathrm{H}_{2}: \mathrm{Ar}$ (1:2:2) to $\mathrm{H}_{2}: \operatorname{Ar}(2: 3)$ at $50 \mathrm{ml}^{-m^{-1}}$.

However, as a preliminary assessment of the quantitative power of the method the $\mathrm{CO}_{\mathrm{ad}}$ species were first isolated from the formate in-situ by purging in $\mathrm{Ar}$ after $\mathrm{CO}_{2}$ methanation. Although the IR intensities of both species were reduced, the formate was removed 
more selectively. The flow was then switched to $\mathrm{H}_{2}$ and the amount of $\mathrm{CH}_{4}$ was measured and compared to the IR band area for $\mathrm{CO}_{\mathrm{ad}}$ at the instant of switching. The experiment was then repeated for $\mathrm{CO}$ adsorbed from the gas-phase, in which the switch was made to $\mathrm{H}_{2}$ directly with no intervening Ar purge. This resulted in a much stronger IR band at the moment of switching, as shown in Fig.5, and a proportionate increase in $\mathrm{CH}_{4}$. Indeed, the agreement is surprisingly good, the ratio of peak areas being virtually identical to the ratio of recovered $\mathrm{CH}_{4}$ and equal to 0.25 . This would also suggest that the $\mathbb{R}$ peak integrals for $\mathrm{CO}$ on $\mathrm{Ru}$ in this catalyst are proportional to adsorbed concentration, and are not subject to artefacts of the type described recently and generalized for metal-adsorbed $\operatorname{CO}(26)$. An interesting effect is also seen in Fig.5, i.e. the marked induction period before "light-off" for $\mathrm{CH}_{4}$ in the case of $\mathrm{CO}-\mathrm{to}-\mathrm{H}_{2}$ flow switching. This seems to be an extreme manifestation of the well-known inhibitory effect of gas-phase $\mathrm{CO}$ on the kinetics of $\mathrm{CO}$ hydrogenation(21). Evidently, the $C O$ has reached saturation coverage $(\theta=1)$, and the freshlyintroduced $\mathrm{H}_{2}$ cannot compete effectively with the residual gas-phase $\mathrm{CO}$ for adsorption sites and subsequent activation. This also implies that the amount of $\mathrm{CH}_{4}$ recovered (94 $\mu \mathrm{mol})$ should be equivalent to the amount of surface $\mathrm{Ru}$ in the sample, assuming a 1:1 $\mathrm{CO}: \mathrm{Ru}_{\mathrm{s}}$ adsorption stoichiometry. Rough estimates based on the catalyst weight $(0.65 \mathrm{~g})$, and a reduction degree $(-70 \%)$ as reported elsewhere(7) give the total amount of zerovalent metal as $\sim 170 \mu \mathrm{mol}$. Thus, if the recovered $\mathrm{CH}_{4}$ is really equivalent to the surface $\mathrm{Ru}^{0}$, an estimate of the metal dispersion is obtained, $D=94 / 170$ or 0.55 . This value is in fair agreement with those estimated from electron microscopy and/or chemisorption $(7,16)$, and serves as a check on the viability of this IR method for surface-titration and its implicit assumptions. On the above basis, i.e. a linear relation between IR band area and surface coverage, the steady-state coverage of $\mathrm{Ru}$ by $\mathrm{CO}$ in $\mathrm{CO}_{2}$ methanation is $\theta=0.4$.

\section{Steady-state kinetics.}

Methanation rate data in the Arrhenius form for a flow mixture containing $10 \mathrm{~mol} \% \mathrm{CO}_{2}$ and $40 \mathrm{~mol} . \% \mathrm{H}_{2}$ showed good linearity and an apparent activation energy of $19.3 \pm 1.0 \mathrm{kcal}$.mol ${ }^{-1}$, consistent with literature values for supported noble metals ranging from $15-25$ kcal.mol.-1 $(13,15,19,27)$.

More interesting is a plot of rate dependence, together with $\theta_{\mathrm{CO}}$, on hydrogen partial pressure over a range of temperatures (see Fig.6). It is remarkable in that the latter is relatively constant over a wide range of temperature (and methanation rate), except at very low $\mathbf{P}_{\mathrm{H} 2}$.

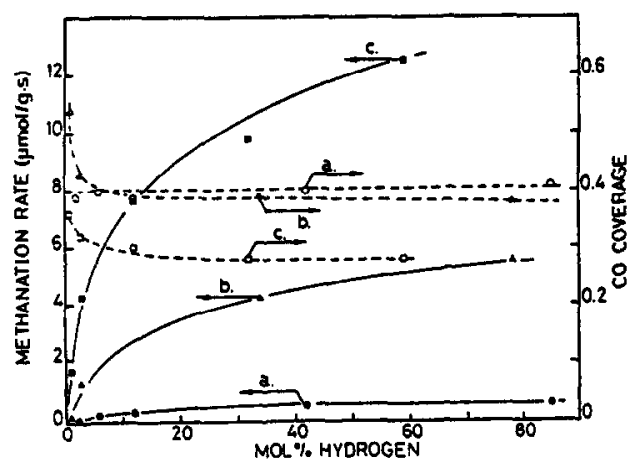

Fig.6. Dependences of steady-state $\mathrm{CO}_{2}$ methanation rate and fractional coverage of metal by $\mathrm{CO}\left(\theta_{\mathrm{CO}}\right)$ on $\mathrm{H}_{2}$ partial pressure $\left(\mathrm{P}_{\mathrm{CO} 2}=0.13\right)$ at a. $120^{\circ} \mathrm{C}, \mathrm{b} .165^{\circ} \mathrm{C}$, and c. $190^{\circ} \mathrm{C}$.

The transient data already show that $\mathrm{CO}$ is clearly the primary intermediate in $\mathrm{CO}_{2}$ methanation, and the lack of influence of rate on $\theta_{\mathrm{CO}}$ has been interpreted elsewhere in terms of a balanced supply/ consumption model in which the activation energies are 
closely-matched(28). Supporting evidence for such a possibility derives from typical literature values for the reverse water gas shift reaction and $C O$ hydrogenation over supported $\mathrm{Ru}$ of $22-25 \mathrm{kcal} . \mathrm{mol}^{-1}(22)$. In the limit of low $\mathrm{P}_{\mathrm{H} 2}$, the up-swing in $\theta_{\mathrm{CO}}$ indicates that the supply step becomes dominant, presumably reflecting differences in the order dependence on $\mathrm{P}_{\mathrm{H} 2}$, i.e. a higher positive order for the $\mathrm{CO}$ consumption step, for which there is also literature evidence(22).

For $\mathrm{CO}_{2}$ methanation the orders of reaction w.r.to hydrogen and carbon dioxide were 0.43 \pm 0.05 and zero, respectively, and independent of temperature in the range examined, i.e. $120-190^{\circ} \mathrm{C}$. The turnover number at $200^{\circ} \mathrm{C}$ was determined as $1.53 \times 10^{-1}$ molecules metal site $e^{-1} \mathrm{~s}^{-1}$. This value is remarkably high even for supported $\mathrm{Ru}$. These authors are not aware of other data for the $\mathrm{Ru} / \mathrm{TiO}_{2}$ system, but a comparison can be made with an estimate for $\mathrm{Ru} / \mathrm{Al}_{2} \mathrm{O}_{3}$ of $0.13 \times 10^{-1}$ molecules metal site $\mathrm{s}^{-1}$, taken from the kinetic expression given in ref.13. Recent studies have confirmed this value for $\mathrm{Ru} / \mathrm{Al}_{2} \mathrm{O}_{3}$ samples prepared in this Institute, despite the fact that the CO coverage of $\mathrm{Ru}_{s}$ in steady-state ( $\theta$ $\Rightarrow 0.2$ ) was not dissimilar to that for $\mathrm{Ru} / \mathrm{TiO}_{2}$ and the activation energies were identical(23). It is also pertinent to state here that turnover numbers for $\mathrm{CO}$ hydrogenation only begin to approach these values at much higher temperatures, typically around $300^{\circ} \mathrm{C}$ (see, e.g. ref.22).

Finally, the irreproducible development of the $\mathrm{CO}_{2 d}$ band in the absence of catalyst precleaning, referred to earlier, must be incorporated into the total picture. The logical inference is that there is an unseen intermediate, possibly atomic $\mathrm{C}$, formed from $\mathrm{CO}_{\mathrm{ad}}$ but at a rate effectively zero-order in $\mathrm{CO}_{\mathrm{ad}}$. This would be the case if a distinct heterogeneity of active sites exists on the metal surface. Previous evidence for heterogeneity in $\mathrm{CO}$ hydrogenation over supported-metal catalysts derives from kinetic modelling studies(29). Furthermore, $\mathrm{CO}$ dissociation has recently been shown to be structure-sensitive over $\mathrm{Ru}(30)$. The role of the $\mathrm{TiO}_{2}$ support could then be to stabilize $\mathrm{Ru}$ in sufficiently high dispersion to optimize the surface density of active sites. An interpretation in terms of an electronic effect such as SMSI is discounted on the basis of the identical activation energies for $\mathrm{Al}_{2} \mathrm{O}_{3}$ and $\mathrm{TiO}_{2}$ and the low-temperature preparation of the catalyst(31).

In summary, most of the $\mathrm{CO}_{2 d}$ seen by DRIFT spectroscopy in $\mathrm{CO}_{2}$ methanation is probably not reacting at steady-state although it is able to migrate to the active sites and undergo reaction during transient hydrogenation. Chemisorbed $\mathrm{H}$ must be available, first to activate $\mathrm{CO}_{2}$ reduction to $\mathrm{CO}$ (via formate), and then to hydrogenate $\mathrm{CO}_{2 d}$, or $\mathrm{C}_{\mathrm{ad}}$, if $\mathrm{C}-\mathrm{O}$ bond dissociation precedes $\mathrm{C}$-H bond formation. This scheme is similar to that proposed by Solymosi et al.(19) except here we include active reservoirs of $\mathrm{CO}_{\mathrm{ad}}$ and $\mathrm{HCOO}_{\mathrm{ad}}{ }^{-}$en route to $\mathrm{CH}_{4}$.

In conclusion, the power and versatility of the DRIFTS/recycle reactor arrangement has been illustrated in this model study of $\mathrm{CO}_{2}$ methanation. The system is ideal for determining steady-state kinetics over a wide range of conversion and is amenable to transient experiments, which are important for mechanistic investigations and for quantitative determination of active surface areas via reactive titration of sorbed material. These authors believe that the system described represents a real step forward in the domain of insitu catalytic process research and has good prospects for extension into the valuable hightemperature regime, i.e. $300-500^{\circ} \mathrm{C}$, typical of many industrial catalytic processes. 


\section{ACKNOWLEDGEMENTS}

Funding for this work was provided by the Swiss National Foundation. We are grateful to

Dr.K.R.Thampi for the provision of the catalyst and helpful discussion.

\section{REFERENCES}

1. N.D.Parkyns and D.I.Bradshaw, in H.A.Willis, J.H.van der Maas and R.G.J.Miller(Eds.), Laboratory Methods in Vibrational Spectroscopy, Wiley, New York, 1987, Chap.16 and references cited therein.

2. M.A.Vannice, S.Moon, C.Twu and S.-Y.Wang, J.Phys.E.Sci.Instrum., 12 (1979) 849.

3. P.R.Griffiths and J.A.de Haseth, Fourier-Transform Infrared Spectrometry, Chemical Analysis Vol.83, Wiley-Interscience, 1986, Chap.17.

4. H.Hoser, A.Innocenti, A.Riva and F.Trifiro, Appl.Catal., 30 (1987) 11.

5. E.Denneulin, C.Bremard, C.Depecker and P. Legrand, Mikrochim.Acta 2 (1988) 113.

6. J.J.Venter and M.A.Vannice, Appl.Spectrosc., 42 (1988) 1096.

7. J.G.Highfield, P.Ruterana, K.R.Thampi and M.Graetzel, in C.Morterra, A.Zecchina and G.Costa(Eds.), Structure and Reactivity of Surfaces, Studies in Surface Science and Catalysis, vol.48, Elsevier, Amsterdam, 1989, p.469.

8. J.J.Venter and M.A.Vannice, J.Phys.Chem., 93 (1989) 4158.

9. C.J.G.van der Grift, J.W.Geus, M.J.Kappers and J.H.van der Maas, Catal.Lett., 3 (1989) 159.

10. K.C.Pratt, in J.R.Anderson and M.Boudart(Eds.), Catalysis, Science and Technology, vol.8., Springer-Verlag, Berlin, 1987, p.207ff and references cited therein.

11. K.Tamaru, Dynamic Heterogeneous Catalysis, Academic Press, London, 1978.

12. D.J.Kaul and E.E.Wolf, Chem.Engng.Sci., 41 (1986) 1101.

13. F.Solymosi,A.Erdohelyi and M.Kocsis, J.C.S.Faraday.Trans.I., 77 (1981) 1003.

14. C.S.Kellner and A.T.Bell, J.Catal., 71 (1981) 296.

15. M.A.Henderson and S.D.Worley, J.Phys.Chem.,89 (1985) 1417.

16. K.R.Thampi, J.Kiwi and M.Graetzel, Nature, 327 (1987) 506.

17. M.Halmann, in M.Graetzel(Ed.), Energy Resources Through Photochemistry and Catalysis, Academic Press, New York, 1983, chap.15, p.507.

18. W.M.Ayers(Ed.),Catalytic Activation of Carbon Dioxide,A.C.S.Symp.Ser., 363 (1987).

19. A.Erdohelyi, M.Pasztor and F..Solymosi, J.Catal., 98 (1986) 166.

20. G.H.Yokomizo, C.Louis and A.T.Bell, J.Catal., 120 (1989) 1.

21. G.Busca,J.Lamotte, J.-C.Lavalley and V.Lorenzelli, J.Am.Chem.Soc.,109 (1987) 5197.

22. M.A.Vannice, in J.R.Anderson and M.Boudart(Eds.), Catalysis, Science and Technology, Vol.3, Springer-Verlag, New York, 1982, p.139.

23. M.R.Prairie, A.Renken, J.G.Highfield, K.R.Thampi and M.Graetzel, J.Catal., in press.

24. E.Guglielminotti, G.Spoto and A.Zecchina, Surface Sci., 161 (1985) 202.

25. R.F.Howe, private communication.

26. P.Hollins, Spectrochim.Acta, 43A (1987) 1539.

27. G.D.Weatherbee and C.H.Bartholomew, J.Catal., 87 (1984) 352.

28. M.R.Prairie, J.G.Highfield and A.Renken, Chem.Engng.Sci., 1991, in press.

29. S.V.Ho and P.Harriott, J.Catal., 64 (1980) 272.

30. E.Shincho, C.Egawa, S.Naito and K.Tamaru, Surface Sci., 155 (1985) 153.

31. G.C.Bond and R.Burch, in Catalysis, SpecPer.Rep., Royal Society of Chemistry, Vol.6., 1983, p.27. 